\title{
Attempt for explanation of declining labor force participation of women in Turkey through test of Under-Participation Trap Hypothesis, applied on microfinance survey data
}

\author{
Tomáš Hes*, Alena Neradová ${ }^{* *}$, Karel Srnec ${ }^{* * *}$ \\ Institute of Tropics and Subtropics, Czech University of Life Sciences Prague, Kamýcká 129, \\ 165 21, Prague 6, Czech Republic \\ *,**,***Tel.: +420 224382164, +420224382503, +420 224382161 \\ ${ }^{*, * * * * * E-m a i l ~ a d d r e s s: ~ t h e s @ m y e l e n . c o m ~, ~ n e r a d o v a a @ i t s . c z u . c z, ~ s r n e c @ i t s . c z u . c z ~}$
}

\begin{abstract}
Labor markets of Turkey are characterized by low female labor force participation when compared with the OECD, neighbour states and EU averages. Besides, the female labor force participation exhibits an unexplained and suprising declining trend in the last decades. The paper attemps to illuminate the phenomenon searching for contingencies in data presented by working women in a microfinance clientele survey in suburban Ankara, especially focusing on status and family related interrelationships that could provide explanation for the low relative number of working women in labor markets of Turkey, testing the Under-participation trap hypothesis.
\end{abstract}

Keywords: CULS; microfinance; funding; Turkey; microcredit; Under Participation Trap; TGMP

\section{INTRODUCTION}

\section{1. Peculiarity of Labor Force Participation of women in Turkey}

Notwithstanding substantial social transformations of the Turkish society in recent decades, the participation of working women, already low by international standards, is decreasing, becoming a phenomenon unparalleled among OECD countries. Despite the changing attitude of men towards working spouses, declining fertility rates, better education of Turkish women and marriages happening at a later age, the share of women seeking or having jobs is on steady decrease in Turkey, from $34.3 \%$ in 1988 to $22 \%$ in 2008 . The labor markets in Turkey thus pave the way for an opposite trend than occurring among OECD countries and present suprising, distinctly lower Labor Force Participation (LFP) rates of women then expected from a dynamic, modernizing country, more so as in the 1980s Turkey enjoyed levels of female LFP similar to developed western economies (World Bank, 2009).

According to the UN Report 48508-TR (UN, 2009) examining the LFP trends in Turkey, urbanization and the decline in agricultural employment are two main factors that have contributed to decrease the share of women in LFP. The women in Turkish urban areas are prevented from employment by unfavourable work conditions that do not permit 
combination of work with childcare and domestic work activities and therefore prefer to stay unemployed. Urbanization leads women to leave high-participation rural environment to a low-participation urban environment, also due to migration of educated young men into better-paid jobs in manufacturing and services, shifting the family activities away from subsistence agriculture and causing a withdrawal of women from the active labor force (4).

The Under-Participation Trap Hypothesis (UPTH) asserts, that female LFP in Turkey remains low due to reduced participation rates among poorly educated women in urban areas, who face complex cultural and economic barriers that constrain their participation in the urban labor market. So, women with low levels of education who are likely to work in informal sector, are offered too low wages to cover additional costs of own childcare and domestic works. Consequently, labor supply is likely to stay low, and low income causes under-investment in education of girls, maintaining the general level of female LFP in an under-participation trap.

\section{RESEARCH}

\section{1. Background of the study}

In August - September 2012, research team from Czech University of Life Sciences (CULS) carried out in coooperation with Turkish microfinance institution TGMP $^{1}$ and SESRIC $^{2}$, subsidiary organ of the Organisation of Islamic Cooperation (OIC) ${ }^{3}$, a survey of the microfinance clientele in the suburban outskirts of Ankara. The survey focused on enterprising women operating in suburbs of bigger Turkish cities, the key segment of microfinance clientele. This sample of data although originally focusing on other topic, was deemed of interest for the study as urbanization, albeit not analyzed yet to detail, is considered one of reason for low FLP in Turkey. Parallely to microfinance related research, the survey data thus permitted assessment of the socio-demographic nature of the gender related FLP in the informal markets of Turkey, expanded in the study. The goal of the study is to confirm UPTH by statistical testing of hypothesis related to level of education, number of household members and number of children within the framework of UPTH, as well as to add additional elements that may enrich UPTH by other elements, such as influence of religion and past experience with microcredit.

\section{2. Methodology}

The study is based upon data retrived from qualitative non-longitudinal questionnaire, converting qualitative responses into discrete interval variables to be examined with standard correlational tools. The survey was completed by 117 active clients, belonging to the stable core of TGMP portfolio of clients, who answered the questions during weekly ordinary repayment sessions of the credit groups under guidance of credit officers. The questionnaire consisted out of 30 closed format questions of dichotomous, rating scale and close-ended importance types, out of which 6 questions were apt for the LFP examination, searching to find correlation between pairs of these.

In order to establish the profile of suitable clients characteristics out from the sample, the answers to 5 selected questions in Tab. 1 deemed to deliver positive value to a MFI in

\footnotetext{
${ }^{1}$ TÜRKIYE GRAMEEN MIKROFINANS PROGRAMI

${ }^{2}$ The Statistical, Economic and Social Research and Training Centre for Islamic Countries

${ }^{3}$ Organization of Islamic Conference
} 
terms of its aptness of the clients to be included in its portfolio, were filtered from the the rest. The selection abstains from speculation by choosing only those topics from the survey that undeniably present a simply understandable plus for any MFI, as depicted below.

The supposition of the paper is that the degree of suitability of clients for MFIs transcends the microfinance sector, providing us with an informative value on conditions which influence women to become job seekers or to work and thus participate in the LFP.

Table 1.

\begin{tabular}{|c|l|c|c|}
\hline $\mathbf{N r}$. & Question & $\begin{array}{c}\text { Desired } \\
\text { answer }\end{array}$ & $\begin{array}{c}\text { \%of } \\
\text { answers }\end{array}$ \\
\hline $\mathbf{1 3}$ & $\begin{array}{l}\text { Is frequency of paying the installments of } \\
\text { microcredit for you } \\
\text { better than frequency of other credits? }\end{array}$ & Yes & 84.00 \\
\hline $\mathbf{1 6}$ & $\begin{array}{l}\text { Do social/ family conventions prevent you from } \\
\text { becoming } \\
\text { a debtor? }\end{array}$ & No & 89.11 \\
\hline $\mathbf{2 3}$ & $\begin{array}{l}\text { Does the fact that you are taker of microcredit } \\
\text { harm your } \\
\text { family/ neighbour relationships? }\end{array}$ & No & 96.00 \\
\hline $\mathbf{2 4}$ & $\begin{array}{l}\text { Do you recommend your economic active } \\
\text { neighbours to take } \\
\text { microcredit? }\end{array}$ & $\begin{array}{l}\text { Yre you holder of more than one microcredit at the } \\
\text { same time? }\end{array}$ & No \\
\hline $\mathbf{2 6}$ & & 58.59 \\
\hline
\end{tabular}

In order to test the results on interdependence through statistical methods, we apply the Chi-square test, a measure of the discrepancy between the observed results and hypothetically expected results, with the $\mathrm{H}_{0}$ of no correlation between the group samples. Four hypothesis were formulated $\left(\mathrm{H}_{1}, \mathrm{H}_{2}, \mathrm{H}_{3}, \mathrm{H}_{4}, \mathrm{H}_{5}\right.$, $)$, in order to determine their probability of truth.

$$
\chi^{2}=\sum \frac{(\mathrm{O}-\mathrm{E})^{2}}{\mathrm{E}}
$$

$\mathrm{O}=$ the observed value

$\mathrm{E}=$ the expected value

\section{3. Hypothesis $\mathrm{H}_{1}$ formulation}

The UPTH supposes that women living in urban areas with low levels of education are more likely to work in informal sector, are offered too low wages to cover additional costs of childcare. We can thus formulate a hypothesis $\mathrm{H}_{1}$ : 
The higher is the number of children in the family, the lower is desirability of women to become microfinance clients and thus the lower is female labor force participation.

\section{4. Hypothesis $\mathrm{H}_{2}$ formulation}

The UPTH postulates that low level of labor participation is particularly relevant for women with low education levels, who are offered low jobs work with low remuneration, thus steering the unemployed away for employment. We formulate a hypothesis $\mathrm{H}_{2}$ :

The less educated women are the more desirable they are as microfinance clients and the more is the probability of falling into UPTH .

\section{5. Hypothesis $\mathrm{H}_{3}$ formulation}

The UPTH presumes that the costs of family maintenance is too high for women earning offered too low wages to cover additional household maintenance costs to the costs childcare. The intensity of household care are causing women to steer away from employment. We can thus formulate a hypothesis $\mathrm{H}_{3}$ :

The higher is the number of people living in the household, the lower is the propensity of women for labor force participation.

\section{6. Hypothesis $\mathrm{H}_{4}$ formulation}

Additionaly to UPTH, correlation with the past experience of women women with microcredit and their suitability of auto-employment through microcredit is an important factor. We can thus formulate a hypothesis $\mathrm{H}_{4}$ :

Experience with microcredit in the past increases the suitability of women as microfinance clients and thus in labor force participation.

\section{7. Hypothesis $\mathrm{H}_{5}$ formulation}

Additionaly to UPTH, the relationship with religious leader implies impact on presumes that the costs of family maintenance is too high for women earning offered too low wages to cover additional costs of childcare. The costs of children ubringing are causing women to steer away from employment. We can thus formulate a hypothesis $\mathrm{H}_{5}$ :

Relationship with religious authorities influences the propensity of women for labor force participation.

\section{TESTING OF HYPOTHESIS $\mathrm{H}_{1}, \mathrm{H}_{2}, \mathrm{H}_{3}, \mathrm{H}_{4}, \mathrm{H}_{5}$}

\section{1. Testing of $\mathrm{H}_{1}$}

The two-sided asymptotic significance of the chi-square statistic reaches 0,521 and thus is greater than level of confidence of 0.95 (10 degrees of freedom), which implicates that we cannot statistically confirm the relationship between the number of children and the propensity of women, who are represented by microfinance clients of TGMP, towards selfemployment and we thus accept $\mathrm{H}_{0}$ hypothesis. 
Table 2.

\begin{tabular}{|c|c|c|c|}
\hline & Value & $\mathrm{df}$ & Asymp. Sig. (2-sided) \\
\hline $\begin{array}{c}\text { Pearson Chi- } \\
\text { square }\end{array}$ & 9,118681 & 10 & 0,520879 \\
\hline
\end{tabular}

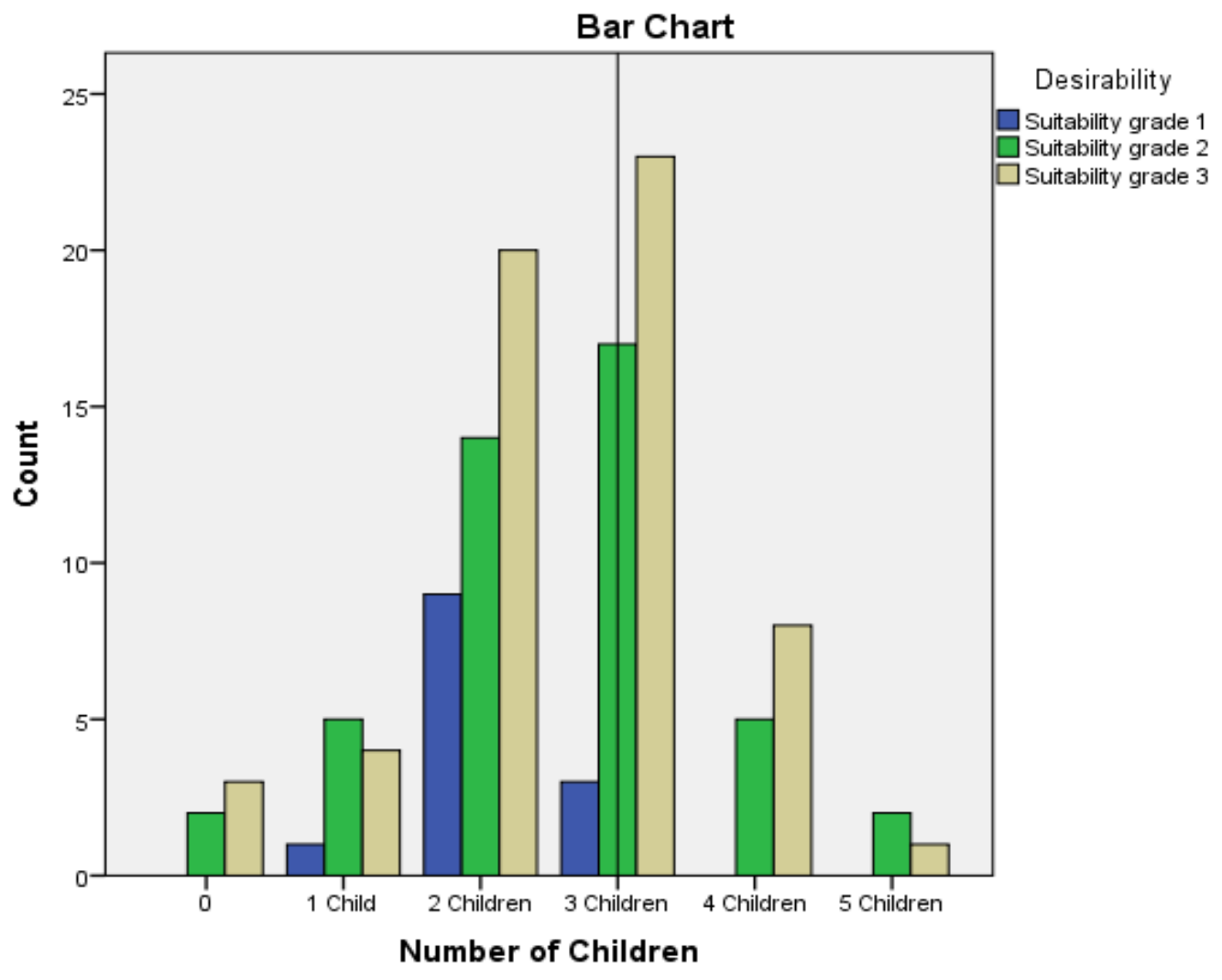

Chart. 1

\section{2. Testing of $\mathbf{H}_{2}$}

The two-sided asymptotic significance of the chi-square statistic reaches 0,88 and thus is greater than level of confidence of 0.95 (12 degrees of freedom), which implicates that we cannot statistically confirm the relationship between the education and the propensity of women, who are represented by microfinance clients of TGMP, towards self-employment and we thus accept $\mathrm{H}_{0}$ hypothesis, not confirming the $\mathrm{H}_{2}$ hypothesis. 
Table 3.

\begin{tabular}{|c|c|c|c|}
\hline & Value & $\mathrm{df}$ & Asymp. Sig. (2-sided) \\
\hline $\begin{array}{c}\text { Pearson Chi- } \\
\text { square }\end{array}$ & 6,005994 & 8 & 0,646560 \\
\hline
\end{tabular}

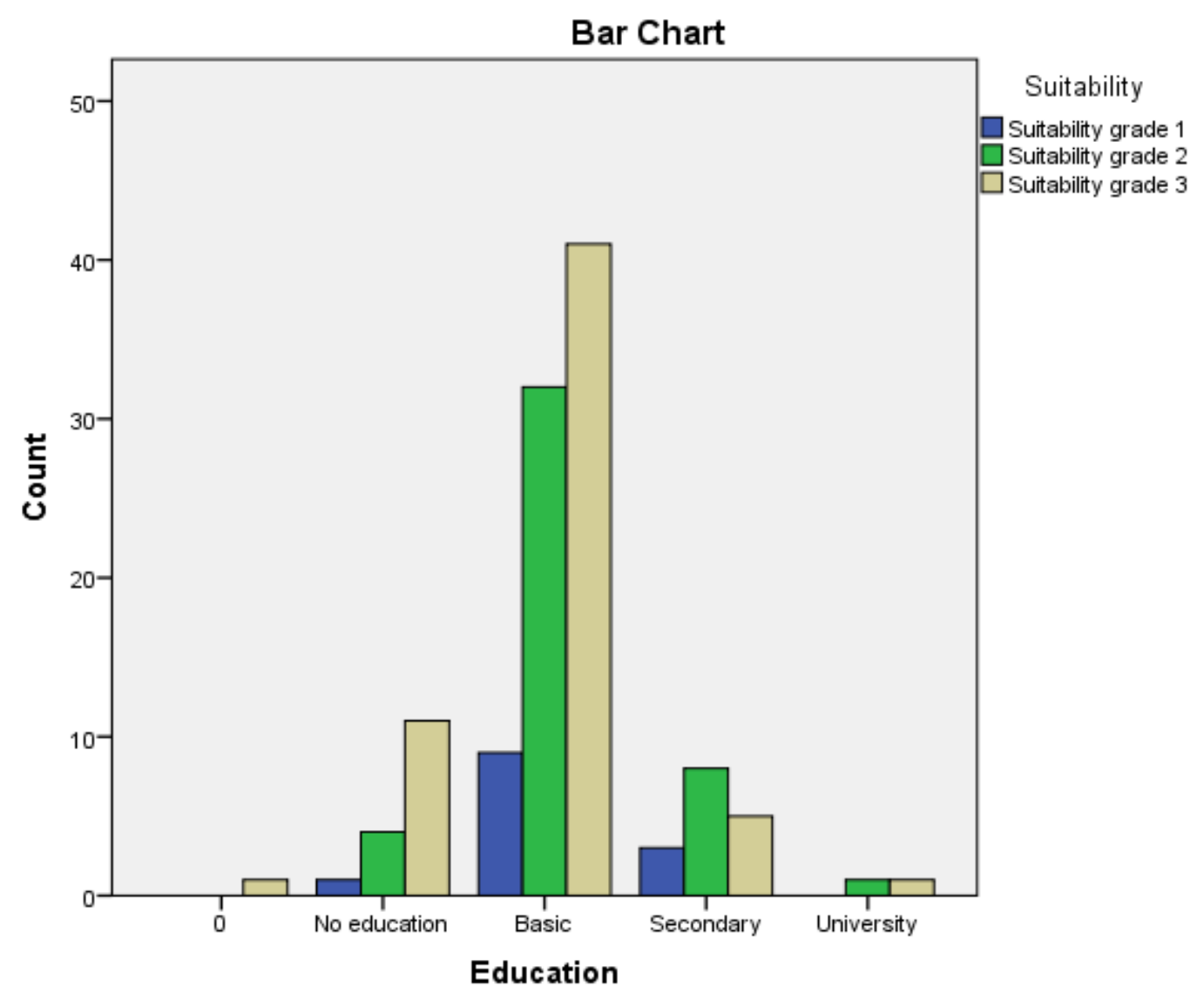

Chart. 2.

\section{3. Testing of $\mathrm{H}_{3}$}

The two-sided asymptotic significance of the chi-square statistic reaches 0,88 and thus is greater than level of confidence of 0.95 (12 degrees of freedom), which implicates that we cannot statistically confirm the relationship between the number of people living in the household and the propensity of women, who are represented by microfinance clients of TGMP, towards self-employment and we thus accept $\mathrm{H}_{0}$ hypothesis, not confirming the $\mathrm{H}_{3}$ hypothesis. 
Table 4.

\begin{tabular}{|c|c|c|c|}
\hline & Value & df & Asymp. Sig. (2-sided) \\
\hline $\begin{array}{c}\text { Pearson Chi- } \\
\text { square }\end{array}$ & 13,961650 & 16 & 0,601571 \\
\hline
\end{tabular}

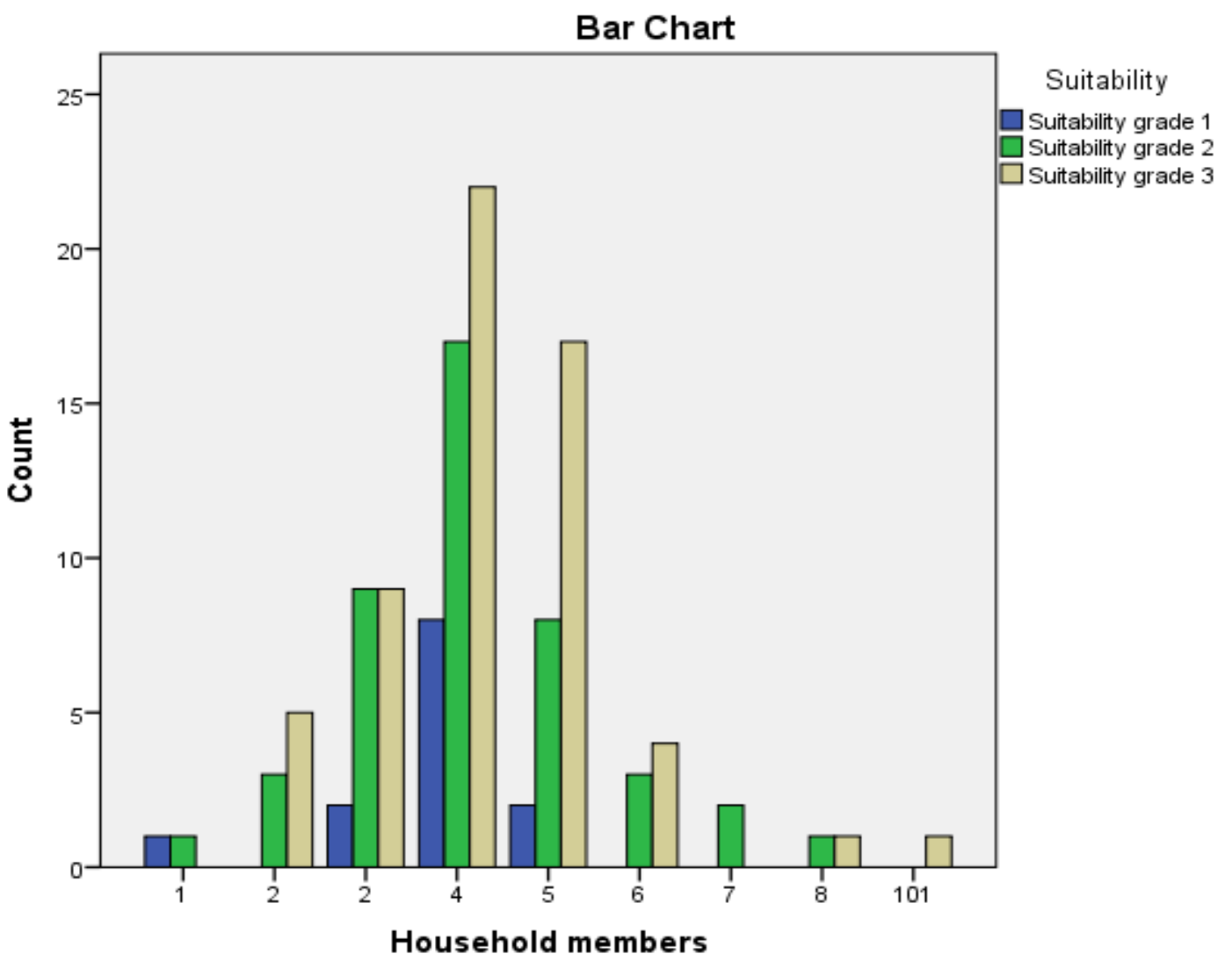

Chart. 3.

The two-sided asymptotic significance of the chi-square statistic reaches 0,88 and thus is greater than level of confidence of 0.95 (12 degrees of freedom), which implicates that we cannot statistically confirm the relationship between the number of people living in the household and the propensity of women, who are represented by microfinance clients of TGMP, towards self-employment and we thus accept $\mathrm{H}_{0}$ hypothesis, not confirming the $\mathrm{H}_{3}$ hypothesis.

Table 4.

\begin{tabular}{|c|c|c|c|}
\hline & Value & df & Asymp. Sig. (2-sided) \\
\hline $\begin{array}{c}\text { Pearson Chi- } \\
\text { square }\end{array}$ & 13,961650 & 16 & 0,601571 \\
\hline
\end{tabular}




\section{4. Testing of $\mathrm{H}_{4}$}

The two-sided asymptotic significance of the chi-square statistic reaches 0,03 and thus is greater than level of confidence of 0.95 ( 2 degrees of freedom), which implicates that we can statistically confirm the relationship between the past use of microcredit and the propensity of women, who are represented by microfinance clients of TGMP, towards selfemployment and we thus reject $\mathrm{H}_{0}$ hypothesis, confirming the $\mathrm{H}_{4}$ hypothesis. The Phi Cramer's measure of 0,258 confirms low strength of dependence.

Table 5.

\begin{tabular}{|c|c|c|c|}
\hline & Value & df & Asymp. Sig. (2-sided) \\
\hline $\begin{array}{c}\text { Pearson Chi- } \\
\text { square }\end{array}$ & 6,868270 & 2 & 0,032253 \\
\hline
\end{tabular}

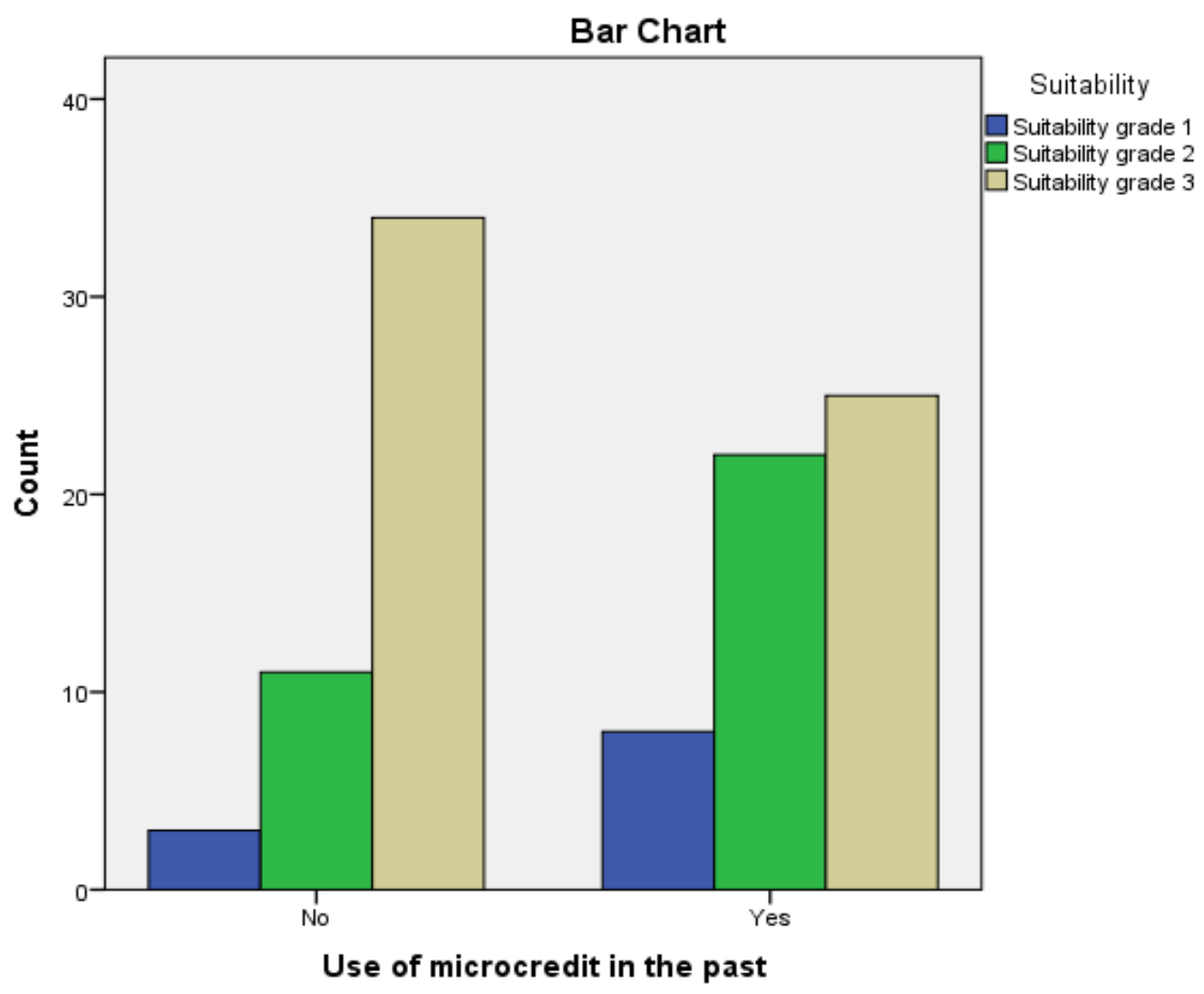

Chart. 4

\section{5. Testing of $\mathrm{H}_{5}$}

The two-sided asymptotic significance of the chi-square statistic reaches 0,0002 and thus is smaller than level of confidence of 0.95 ( 2 degrees of freedom), which implicates that there is relationship between the influence of religious leader and and the propensity of women, who are represented by microfinance clients of TGMP, towards self-employment and 
we thus reject $\mathrm{H}_{0}$ hypothesis, and confirm the $\mathrm{H}_{5}$ hypothesis. The Phi Cramer's measure of 0,378 confirms medium strength of dependence.

Table 6.

\begin{tabular}{|c|c|c|c|}
\hline & Value & $\mathrm{df}$ & Asymp. Sig. (2-sided) \\
\hline Pearson Chi-square & 16,756965 & 2 & 0,000230 \\
\hline
\end{tabular}

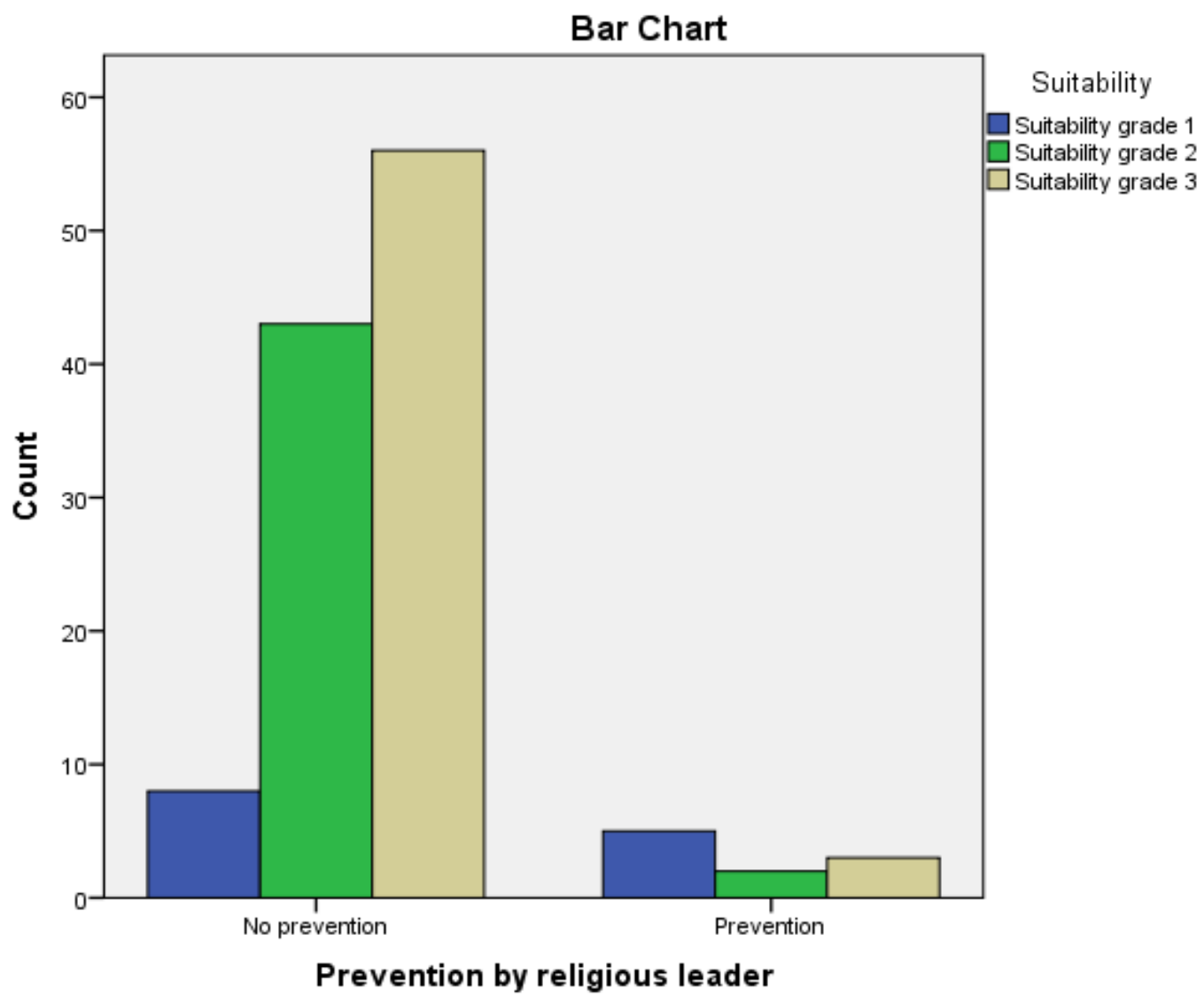

Chart. 5

\section{CONCLUSION}

The study, assuming that the sample of chosen characteristics of female clients of microfinance institutions represent data of informative value also for the non-microfinance clients and thus for labor force participation related topic, did not encounter statistical correlation between the level of education, number of children nor number of household members and the suitability of sample of population of autonomous, enterprising and economically active women, as selected between the clientele of Turkish microfinance institution TGMP. Therefore the Underparticipation trap hypothesis was not confirmed by targeting the mentioned elements, in the search for correlation with the results of the CULS survey field study in Ankara. However, the additional findings confirm interesting correlation of low to middle strength between the influence of religious authorities as well as between 
the past experience and the suitability of clients for MFIs. If such finding can be confirmed in more focused studies, the influence of religious authorities can proven to have an effect on the labor force participation women. Likewise, as demonstrated by the study, experience with microcredit in the past increases the qualities of Turkish women with impact to participate in the labor force.

Concluding, the Under-participation Trap Hypothesis is likely to be complex phenomenon explainable by a fabric of multilayer data inputs rather then by single variables Within these, the study is pointing at religion and work experience as being potentially important elements in the explanation architecture.

\section{Biographical notes:}

Mr. Dipl. Kfm. Tomáš Hes, PhD. Student, is a Czech development economist, with focus on microfinance, graduated in IHI Zittau, Germany. His career entails work in consulting, currency exchange, banking, MFIs and education NGOs in Brazil, Germany, Czech Republic, Romania and Mexico. Currently pursues the build-up of myELEN.com infrastructure, Czech peer to peer on-line microfinance lending platform.

Ing. Alena Neradová, Ph.D. student, graduated in Faculty of Economics and Management in Czech University of Life Sciences Prague. At the time of studies she spent two semesters at ESDES, Ecole de management in Lyon, France - marketing and management specialization. Currently, Mrs. Neradová researches and teaches Banking and finance, Microfinance and rural economics and Economics of agriculture and natural resources. Within her work experience she participates in marketing projects and in developing of banking system.

Mr. Doc.Ing.Karel Srnec, PhD., a Czech economist focused on microfinance, graduated in Czech Agricultural University in Prague. Currently, Mr. Srnec researches and teaches banking, development finance and microfinance on the Institute of Tropics and Subtropics affiliated to Czech Agricultural University in Prague, being member of the board of the institute, with broad experience spanning from agricultural development, Middle East and Africa focused consulting, commercial banking as well as membership in the Czech-Israel chamber of commerce.

\section{References}

[1] World Bank (2009), Female Labor Force Participation in Turkey: Trends, Determinants and Policy Framework.

[2] Turkish statistical institute (2012), http://www.turkstat.gov.tr accessed on 10.2.2012.

[3] Fowlers S. (2011), Women Still an Untapped Labor Force in Turkey, The International Herald Tribune.

[4] Goksel I. (2011), The reason of decreasing trend of female labor force participation in Turkey: The role of conservatism, Izmir University of Economics.

[5] Hes T., Alena Neradová A., Srnec K. (2013), Socio-economic profile of village bank member in suburban Ankara: microcredit mannequin and assumptions on microfinance market of Turkey, International Letters of Social and Humanistic Sciences, Vol. 7, pp. 55-75. 